\section{Stock Market Returns, Volatility, and Future Output}

\author{
Hui Guo
}

$0^{t}$ tock market volatility is the systematic risk faced by investors who hold a market portfolio (e.g., a stock market index fund). Schwert (1989b) has undertaken an extensive study of stock market volatility, using historical data back to the 19th century. Some of his major findings are illustrated in Figure 1, which plots quarterly stock market volatility for the post-World War II period. ${ }^{1}$ The figure shows that volatility moves countercyclically, exhibiting spikes during recessions. Also, stock market volatility tends to increase dramatically during financial crises (such as the 1987 stock market crash, the 1997 East Asia crisis, and the 1998 Russian bond default) and periods of uncertainty (such as the 1962 Cuban missile crisis). Moreover, volatility, once risen, shows some inertia in that it reverts only slowly to its previous, low level.

Although the causes of stock market volatility are not well understood, some authors suggest that elevated stock market volatility might reduce future economic activity. ${ }^{2}$ Schwert (1989a) argues that stock market volatility, by reflecting uncertainty about future cash flows and discount rates, provides important information about future economic activity. Campbell et al. (2001), citing work by Lilien (1982), reason that stock market volatility is related to structural change in the economy. Structural change consumes resources, which depresses gross domestic product (GDP) growth. Another link between stock market volatility and output rests on a cost-of-capital channel. That is, an increase in stock market volatility raises the compensation that shareholders demand for bearing systematic risk. The higher expected return leads to the higher cost of equity capital in the corporate sector, which reduces investment and output. Consistent with these hypotheses about the link between stock market volatility and economic activity, Campbell

Hui Guo is an economist at the Federal Reserve Bank of St. Louis. The author thanks Frank Schmid for helpful comments. William Bock provided research assistance.

(C) 2002, The Federal Reserve Bank of St. Louis.

\section{Figure 1}

\section{Realized Stock Market Variance}

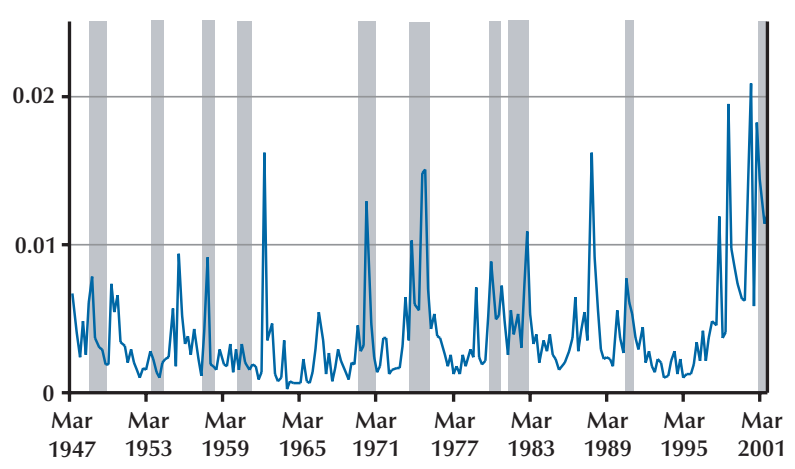

NOTE: Quarterly observations, 1947:Q2 through 2001:Q3; shaded areas indicate recessions dated by the National Bureau of Economic Research. See footnote 1 on adjustments to the October 1987 stock market crash.

et al. (2001) show that-after controlling for the lagged dependent variable-stock market volatility has significant predictive power for real GDP growth. Moreover, these authors also show that stock market volatility drives out returns in forecasting output. This finding deserves discussion.

Finance theory suggests that stock market returns rather than volatility have predictive power for investment and output because stock market returns are a forward-looking variable that incorporates expectations about future cash flows and discount rates. Several studies have confirmed the predictive power of stock market returns for investment and output, among them Fama (1981), Fischer and Merton (1984), and Barro (1990). On the other hand, the finding of Campbell et al. about the predictive power of stock market volatility for future economic activity is new, but the authors do not provide a theoretical explanation for the evidence. In this article, I try to reconcile the results of Campbell et al. with earlier empirical evidence on the predictive power of stock market returns and finance theory.

\footnotetext{
1 The stock market variance for 1987:Q4 amounts to several times more than the second-largest quarterly realization; this is due to a spike in volatility associated with the stock market crash on October 19, 1987. I follow Campbell et al. (2001) in replacing the variance of 1987:Q4 by the largest realized variance in the sample prior to $1987: \mathrm{Q} 4$, and I make this adjustment throughout the paper. Appendix A describes the data.

2 Shiller (1981) argues that stock prices are more volatile than what is justified by time variation in dividends. Similarly, Schwert (1989b) concludes that stock market volatility cannot be fully explained by changes in economic fundamentals.
} 
I first use Merton's (1973) Intertemporal Capital Asset Pricing Model (ICAPM) to illustrate the relation between stock market returns and volatility. I show that excess stock market returns, the difference between stock market returns and a risk-free rate, are positively correlated with one-period-lagged variance, but are negatively correlated with contemporaneous variance. These results have been well understood in the literature (e.g., Pindyck, 1988). Past variance relates positively to excess returns because it contains information about conditional variance or risk. The contemporaneous relation between excess returns and variance is negative because of a volatility feedback effect. That is, a positive innovation in variance today implies higher expected future variance and, therefore, higher expected future returns. For future expected returns to be higher, the innovation in variance must be accompanied by a drop in the stock market price index. Early authors (e.g., Pindyck, 1988; Turner, Startz, and Nelson, 1989; and Dueker, 1991) have found some support for this hypothesized risk-return relation. However, while Turner, Startz, and Nelson (1989) and Dueker (1991) impose no model restrictions on the coefficients of the variance terms, Pindyck (1988) finds that data reject these restrictions over some sample periods. In this paper, I find that (i) past stock market variance has significant forecasting ability for excess returns; (ii) the risk price is found to be positive and precisely estimated; and (iii) the model restrictions are not rejected by data.

After establishing the relation between excess returns and variance, it is straightforward to explain why stock market volatility drives out returns in forecasting output. According to the $q$ theory of investment, an increase in stock market variance reduces investment-and hence output-contemporaneously because it raises the cost of capital. Lamont (2000), however, argues that investment expenditures react to changes in the cost of capital with lags. Therefore, stock market variance is negatively correlated with future investment and output. For the same reason, excess returns are expected to correlate positively with future output because excess returns correlate negatively with variance. It should be noted that excess returns-unlike variance-are hampered in their predictive power for future output because excess returns correlate positively with past variance, which in turn correlates negatively with future output. Because of these opposing effects, the predictive power of excess returns for future output is not as strong as the pre- dictive power of variance. However, if the positive relation between excess returns and past variance is controlled for (i.e., adding past variance to the forecasting equation), excess returns might become significant and might even drive out variance because variance provides no additional information beyond excess returns in forecasting output.

I replicate the Campbell et al. (2001) resultthat excess stock market returns are statistically insignificant in predicting GDP growth if stock market variance is also included in the forecasting equation-for the period 1963:Q1 to 1997:Q4. However, as postulated, I find that excess returns change from insignificant to marginally significant when I control for the lagged variance in the forecasting equation, meanwhile stock market variance changes from significant to marginally significant. ${ }^{3}$ I also analyze two more sample periods. One sample covers the entire postwar period (1947:Q2 to 2000:Q4), while the other sample spans the longest available time period, ranging from $1885: \mathrm{Q} 4$ to 2000:Q4. For these two sample periods, I find that excess returns actually drive out variance in forecasting output growth; moreover, only return terms are statistically significant if I also add past returns and past variance to the forecasting equation. Finally, the formal out-of-sample forecast test rejects the null hypothesis that excess returns provide no information about future GDP growth beyond what is contained in variance. These results should not be a surprise. As mentioned above, from the cost-ofcapital point of view, volatility contains no additional information beyond excess returns; however, excess returns contain additional information (e.g., information about future cash flows) beyond variance in forecasting output.

In the article, I investigate the empirical link between stock market returns and volatility, analyze their relative forecasting power for output, and offer some concluding remarks.

\section{EXCESS STOCK MARKET RETURNS AND VARIANCE}

Merton (1973) shows that risk-averse investors demand extra compensation for bearing extra risk, everything else equal. Following Merton (1980), I assume that there is a linear positive relation between the stock market risk and return:

\footnotetext{
3 If we extend the sample period to $2000: \mathrm{Q} 4$, we find that the return term becomes significant while the variance term becomes insignificant.
} 


$$
E_{t} e_{M, t+1}=\gamma E_{t} \sigma_{M, t+1}^{2},
$$

where $E_{t} e_{M, t+1}$ is the conditional excess stock market return or the difference between the conditional return, $E_{t} r_{M, t+1}$, and a risk-free rate, $r_{f, t+1} ; E_{t} \sigma_{M, t+1}^{2}$ is the conditional stock market variance; and $\gamma>0$ is a measure of relative risk aversion. The degree of risk aversion can be interpreted as a price for risk.

Equation (1) holds exactly in the static Capital Asset Pricing Model (CAPM); however, in Merton's (1973) ICAPM, it holds only if investment opportunities are constant over time. In general, the expected return, $E_{t} e_{M, t+1}$, has an additional component reflecting the hedge demand for time-varying investment opportunities. Merton (1980) provides conditions under which the hedge component of excess returns is negligible, and equation (1) has been extensively utilized in the empirical literature.

Early work on the risk-return relation stated in equation (1) has come up with conflicting results. For example, while French, Schwert, and Stambaugh (1987) find a positive risk-return relation using an autoregressive conditional heteroskedasticity (ARCH) in mean model, Campbell (1987) documents a negative relation using an instrumental variable approach. Recent research by Scruggs (1998) and Guo (2002) suggests that the negative relation between stock market risk and return is an artifact of ignoring the hedge component of excess returns, which relates negatively to the risk component. After controlling for the hedge component in equation (1), these authors show that risk and return are indeed positively correlated. Moreover, Guo (2002) finds that high past stock market variance indeed forecasts high excess returns using quarterly data, although this relation is weakened by the hedge component. To focus on the issue of interest, I ignore the hedge component in this section and confine the analysis to the risk-return relation specified in equation (1), which is also the most widely used specification in the literature.

Existing empirical evidence suggests that stock market variance is serially correlated. To be parsimonious, I model the serial correlation as an AR(1) process, as in Pindyck (1988) and many others:

$$
\sigma_{M, t+1}^{2}=\alpha+\beta \sigma_{M, t}^{2}+\varepsilon_{t+1} .
$$

Using the log-linearization method discussed in Campbell, Lo, and MacKinlay (1997), Guo and Whitelaw (2001) show that equations (1) and (2) imply

$$
e_{M, t+1} \approx \gamma \alpha+\gamma \beta \sigma_{M, t}^{2}-\frac{\gamma \rho \beta}{1-\rho \beta} \varepsilon_{t+1}+\eta_{d, t+1},
$$

where $\rho$ is a constant slightly less than 1 and $\eta_{d, \mathrm{t}+1}$ is the shock to expected future dividend growth. ${ }^{4}$ Equation (3) shows past variance can be used to forecast excess returns because past variance contains all the information about expected future variance and, hence, expected future excess return. It also shows that movements in excess returns are explained by past variance, shocks to variance, and shocks to dividend growth. In other words, the excess return at time $t+1$ is high because (i) expected return or variance at time $t$ is high, (ii) there is a negative shock to variance at time $t+1$, and (iii) future dividend growth is expected to be higher than previously thought.

After rearranging terms, equation (3) can also be rewritten as

(4)

$$
e_{M, t+1} \approx \frac{\gamma \cdot \alpha}{1-\rho \cdot \beta}+\frac{\gamma \beta}{1-\rho \beta} \sigma_{M, t}^{2}-\frac{\gamma \rho \beta}{1-\rho \beta} \sigma_{M, t+1}^{2}+\eta_{d, t+1} .
$$

Equation (4) shows that the excess return, $e_{M, t+1}$, is positively correlated with past variance, $\sigma_{M, t}^{2}$, and negatively correlated with contemporaneous variance, $\sigma_{M, t+1}^{2}$. As mentioned, the negative relation between excess returns and variance is caused by the serial correlation in variance or the volatility feedback effect.

Following Campbell et al. (2001), among many others, I measure stock market volatility by the sum of the squared deviations of the daily return on the market portfolio from its (daily) mean return. This volatility measure, as advocated by Merton (1980), is unbiased and can be arbitrarily accurate with sufficiently high-frequency data. I also experiment with some other volatility measures discussed in Yang and Zhang (2000), including the volatility estimator using high and low prices. ${ }^{5}$ Interestingly, our measure outperforms the alternatives by a large margin in forecasting one-quarter-ahead excess returns. Moreover, although the alternative volatility measures differ somewhat from the one I use here, they never change the results in any qualitative ways. Many authors also use the volatility implied in stock market index options using the formula provided by Black and Scholes (1973). Unfortunately, historical

4 Appendix B provides details of the deviation of equations (3) and (4).

5 I use the daily high and low prices in Standard \& Poor's 500 index. 


\section{Table 1}

Stock Market Returns and Variance: OLS Regressions

\begin{tabular}{|c|c|c|c|c|}
\hline & Constant & $\sigma_{M, t+1}^{2}$ & $\sigma_{M, t}^{2}$ & $\mathbf{R}^{2}$ \\
\hline \multicolumn{5}{|c|}{ A. 1947:Q2-2000:Q4 } \\
\hline \multirow[t]{2}{*}{ A1 } & $0.001(0.166)$ & & $4.367^{* * *}(2.633)$ & 0.03 \\
\hline & & & & 0.03 \\
\hline \multirow[t]{2}{*}{ A2 } & $0.052 * * *(7.470)$ & $-8.774 * * *(-4.144)$ & & 0.14 \\
\hline & & & & 0.14 \\
\hline \multirow[t]{2}{*}{ A3 } & $0.029 * * *(4.018)$ & $-13.158^{* * *}(-5.287)$ & $10.395^{* * *}(4.649)$ & 0.29 \\
\hline & & & & 0.29 \\
\hline \multicolumn{5}{|c|}{ B. 1963:Q1-1997:Q4 } \\
\hline \multirow[t]{2}{*}{ B1 } & $-0.010(-0.997)$ & & $6.487^{* * *}(3.554)$ & 0.05 \\
\hline & & & & 0.04 \\
\hline \multirow[t]{2}{*}{ B2 } & $0.051^{* * *}(5.052)$ & $-10.503^{* * *}(-3.564)$ & & 0.14 \\
\hline & & & & 0.13 \\
\hline \multirow[t]{2}{*}{ B3 } & $0.022 * *(2.366)$ & $-18.427^{* * *}(-5.480)$ & $16.112^{* * *}(6.640)$ & 0.36 \\
\hline & & & & 0.35 \\
\hline \multicolumn{5}{|c|}{ C. 1885:Q4-2000:Q4 } \\
\hline \multirow[t]{2}{*}{ C1 } & $0.011^{* *}(2.358)$ & & $0.225(0.581)$ & 0.00 \\
\hline & & & & -0.00 \\
\hline \multirow[t]{2}{*}{$\mathrm{C} 2$} & $0.026^{* * *}(3.842)$ & $-2.011 *(-1.830)$ & & 0.05 \\
\hline & & & & 0.05 \\
\hline \multirow[t]{2}{*}{$\mathrm{C} 3$} & $0.019 * * *(3.417)$ & $-3.765^{* * *}(-4.054)$ & $2.688^{* * *}(4.037)$ & 0.10 \\
\hline & & & & 0.10 \\
\hline
\end{tabular}

NOTE: $t$ statistics are reported in parentheses and */***** denote significance at the 10/5/1 percent levels, respectively (two-tailed tests). For the column under $R^{2}$, the first row is $R^{2}$ and the second row is the adjusted $R^{2}$.

data on index options go back to the mid-1980s only. ARCH models are another popular method of estimating stock market volatility. Most appropriate for estimating volatility in high-frequency data, this concept of stock market volatility is less suitable for the purpose here.

I first estimate equations (3) and (4) using ordinary least squares (OLS). That is, I run OLS regressions of excess returns on past variance as in equation (3) and regress excess returns on both past and contemporaneous variance as in equation (4). It should be noted that OLS estimators are potentially biased for equation (4) because contemporaneous variance, $\sigma_{M, t+1}^{2}$, might be correlated with dividend shocks, $\eta_{d, t+1}$. Later, I report the generalized method of moments (GMM) estimation results, which are not vulnerable to the simultaneity problem. To control for serial correlation and heteroskedasticity in the residuals, I correct the standard errors following Newey and West (1987) when calculating t statistics. ${ }^{6}$

I analyze three different sample periods. Panel A in Table 1 represents the postwar sample, 1947:Q2 to 2000:Q4. As expected, although past variance exhibits a positive and statistically significant influence on excess returns in row A1, contemporaneous variance exhibits a negative and statistically significant correlation with excess returns in row A2. In the regression reported in row $\mathrm{A} 3$, both past and contemporaneous variance terms are statistically

\footnotetext{
6 A procedure proposed by Newey and West (1994) is used to choose the appropriate lag length in constructing the covariance matrix.
} 


\section{Table 2}

\section{Stock Market Returns and Variance: GMM Regressions}

$\alpha$

A. 1947:Q2-2000: Q4

$0.499 * * *(8.829)$

$6.331^{* * *}(5.016)$

$\mathrm{R}^{2}$ of return equation: 0.28

$\chi^{2}(3)=5.72(p$ value 0.13$)$

\section{B. 1963:Q1-1997:Q4}

$$
0.001^{* * *}(6.100) \quad 0.625^{* * *}(12.090) \quad 5.868^{* * *}(4.971)
$$

$\mathrm{R}^{2}$ of return equation: 0.36

$\chi^{2}(3)=5.64(p$ value 0.13$)$

\section{1885:Q4-2000:Q4}

$$
0.003^{* * *}(3.677) \quad 0.502^{* * *}(3.847) \quad 1.823^{* *}(2.148)
$$

$\mathrm{R}^{2}$ of return equation: 0.09

$\chi^{2}(3)=6.15(p$ value 0.11$)$

NOTE: $\mathrm{t}$ statistics are reported in parentheses and $* / * * / * * *$ denote significance at the $10 / 5 / 1$ percent levels, respectively (two-tailed tests). $\chi^{2}(3)$ is the statistic of over-identifying restrictions.

significant with expected signs. Interestingly, the $R^{2}$ statistic of 29 percent in row A3 is considerably greater than the $\mathrm{R}^{2}$ statistics of rows $\mathrm{A} 1$ and $\mathrm{A} 2$. Also, the absolute values of coefficients and t statistics of the variance terms in row A3 are much larger than their counterparts in rows A1 and A2. This result can be attributed to the fact that-while variances are positively serially correlated-the effects of past and contemporaneous variance are of opposite signs in the excess return equation. Hence the evidence for a positive risk-return relation is stronger if the volatility feedback effect is controlled for. ${ }^{7}$

For the purpose of comparison, panel B reports the regression results for the sample period analyzed by Campbell et al. (2001), which runs from 1963:Q1 to $1997: Q 4 .{ }^{8}$ The results in panel $\mathrm{B}$ are similar to those in panel A, which is to be expected given the large overlap of the two sample periods. Lastly, panel $\mathrm{C}$ reports regression results for the most extensive available sample, 1885:Q4 to 2000:Q4. While the results in panel $\mathrm{C}$ are qualitatively similar to those in panels $A$ and $B$, it should be noted that the variance terms have somewhat weaker explanatory power. Also, the absolute values of the coefficients of the variance terms are smaller than their counterparts in panels $A$ and $B$.

As mentioned above, the OLS estimates of equa- tion (4) reported in Table 1 might be biased because of a simultaneity problem. Also, it is more interesting to estimate the structural parameter or the price of risk, $\gamma$, rather than the coefficients of the variance terms. However, $\gamma$ cannot be independently identified in equation (4). To address these issues, I use GMM to estimate equations (2) and (4) jointly?:

(5)

$$
\begin{aligned}
& \sigma_{M, t+1}^{2}=\alpha+\beta \sigma_{M, t}^{2}+\varepsilon_{t+1} \\
& e_{M, t+1} \approx \frac{\gamma \cdot \alpha}{1-\rho \cdot \beta}+\frac{\gamma \beta}{1-\rho \beta} \sigma_{M, t}^{2}-\frac{\gamma \rho \beta}{1-\rho \beta} \sigma_{M, t+1}^{2}+\eta_{d, t+1} .
\end{aligned}
$$

The set of instrumental variables includes a constant and two lags in variance, which gives us six restrictions to identify three parameters, $\alpha, \beta$, and $\gamma$. The system is thus overidentified with three degrees of freedom. The GMM regression results are reported

7 Dueker (1991) makes a similar point by showing that the conditional variance is significantly positive (insignificantly negative) in the excess return equation if the contemporaneous variance is (not) controlled for.

8 As in Campbell et al. (2001), I use the daily value-weighted market return data from the Center for Research in Security Prices (CRSP); the data span the period from 1962:Q3 to 1997:Q4. Two lags are used to forecast GDP; therefore, the analysis in Tables 1 through 3 uses data for the period 1963:Q1 to 1997:Q4.

9 Following Campbell et al. (1997), I set $\rho$ equal to 0.99 in quarterly data. 
in Table 2; again, I analyze the aforementioned three sample periods. For all sample periods, all parameters are statistically significant. In particular, the risk price, $\gamma$, is positive and precisely identified. 10 Moreover, the overidentifying restrictions, which have a $\chi^{2}$ distribution with three degrees of freedom, cannot be rejected at conventional significance levels.

\section{EXCESS STOCK MARKET RETURNS, VARIANCE, AND FUTURE OUTPUT}

Table 3 reports the OLS regression results of the one-quarter-ahead real GDP (GNP) growth rate, $\Delta g d p_{t+1}$, on lagged GDP growth, $\Delta g d p_{t}$; excess stock market return, $e_{M, t}$; variance, $\sigma_{M, t}^{2} ;$ and their lags. ${ }^{11}$ Panel B shows the results for the Campbell et al. (2001) sample period 1963:Q1 to 1997:Q4. As shown in rows $\mathrm{B} 1$ and $\mathrm{B} 2$, both excess return, $e_{M, t}$, and variance, $\sigma_{M, t}^{2}$, have significant forecasting ability for the real GDP growth. The forecasting equation in row B3 includes lagged GDP growth, $\Delta g d p_{t}$, excess return, $e_{M, t}$, and variance, $\sigma_{M, t}^{2}$, which is the same specification used by Campbell et al. I confirm that variance drives out excess returns, while lagged GDP growth remains significant. As discussed above, these results may be explained by the positive correlation of excess return, $e_{M, t}$, with past variance, $\sigma_{M, t-1}^{2}$. To investigate this argument further, I add past variance to the forecasting equation, which leads to the regression results shown in row B4. Although insignificant, the coefficient of past variance is negative, as expected. Interestingly, now excess returns change from insignificant to marginally significant in row $B 3$, while variance changes from significant to marginally significant in row B3. As a robustness check, I also add the past return, $e_{M, t-1}$, to the forecasting equation. The regression results of this approach are displayed in row B5, which shows that the past return is statistically significant, as is variance. Inter estingly, if I extend the sample period to 2000:Q4, the return terms are always significant and the variance terms are always insignificant in the specifications of rows B4 and B5. To summarize, stock market variance drives out excess returns in forecasting output because of the positive relation between excess returns and past variance; if this relation is controlled for, excess returns show up significantly in the forecasting equation.

I repeat the analysis of the forecasting power of excess returns and variance for the two other samples mentioned. Panel A in Table 3 represents the full postwar sample. Again, as shown in rows A1 and $\mathrm{A} 2$, both excess return, $e_{M, t}$, and variance, $\sigma_{M, t}^{2}$, have significant forecasting ability for real GDP growth. However, in contrast with the finding in panel B, row A3 shows that excess returns actually drive out variance in the model specification chosen by Campbell et al. (2001). Consistent with the findings in panel $\mathrm{B}$, row $\mathrm{A} 4$ shows that, when past variance is controlled for, both the coefficient and the t statistic of excess returns increase, while the corresponding values of variance decrease in absolute value terms. Row A4 also shows a statistically significant influence of past variance on future output. However, past variance loses its predictive power if I also include past returns in the forecasting equation: only return terms and lagged GDP growth have predictive power in row A5. Panel C reports the regression results using the sample $1885: \mathrm{Q} 4$ to 2000:Q4. This long sample shows that return terms are always significant; also, variance terms are never significant except in row $\mathrm{C} 1$.

Table 3 provides in-sample evidence that excess stock market returns have significant predictive power for one-quarter-ahead GDP growth when I control for stock market variance and lagged GDP growth. The good in-sample fit of the return variable, however, does not guarantee its practical usefulness in output forecasts. To address this issue, I also perform out-of-sample forecast tests for the postwar sample and report the results in Table 4. In the benchmark model of Table 4 (panel A), GDP growth is a function of a constant, lagged GDP growth, variance, and past variance. To investigate whether excess returns provide additional information about future output beyond these variables, I augment the benchmark model by returns and past returns:

Benchmark: $d g d p_{t+1}=f\left(c, d g d p_{t}, \sigma_{M, t}^{2}, \sigma_{M, t-1}^{2}\right)$

Augmented: $d g d p_{t+1}=f\left(c, d g d p_{t}, \sigma_{M, t}^{2}, \sigma_{M, t-1}^{2}, e_{M, t}, e_{M, t-1}\right)$.

Panel B proceeds in the other direction: including the return terms in the benchmark model and then testing whether the variance terms improve the forecast performance,

$$
\begin{aligned}
& \text { Benchmark: } d g d p_{t+1}=f\left(c, d g d p_{t}, e_{M, t}, e_{M, t-1}\right) \\
& \text { Augmented: } d g d p_{t+1}=f\left(c, d g d p_{t}, \sigma_{M, t}^{2}, \sigma_{M, t-1}^{2}, e_{M, t}, e_{M, t-1}\right) .
\end{aligned}
$$

\footnotetext{
${ }^{10}$ The price of risk is estimated to be slightly smaller here (panel A) than in Guo (2001) because the hedge component, which may have a nonzero mean, was included there. Interestingly, if a constant term is added to equation (4) as an additional parameter, the estimated risk price is close to that in Guo (2001).

${ }^{11}$ GNP data is used for the long sample only, which covers the period 1885:Q4 to 2000:Q4.
} 


\section{Table 3}

\section{Forecasting One-Quarter-Ahead GDP Growth}

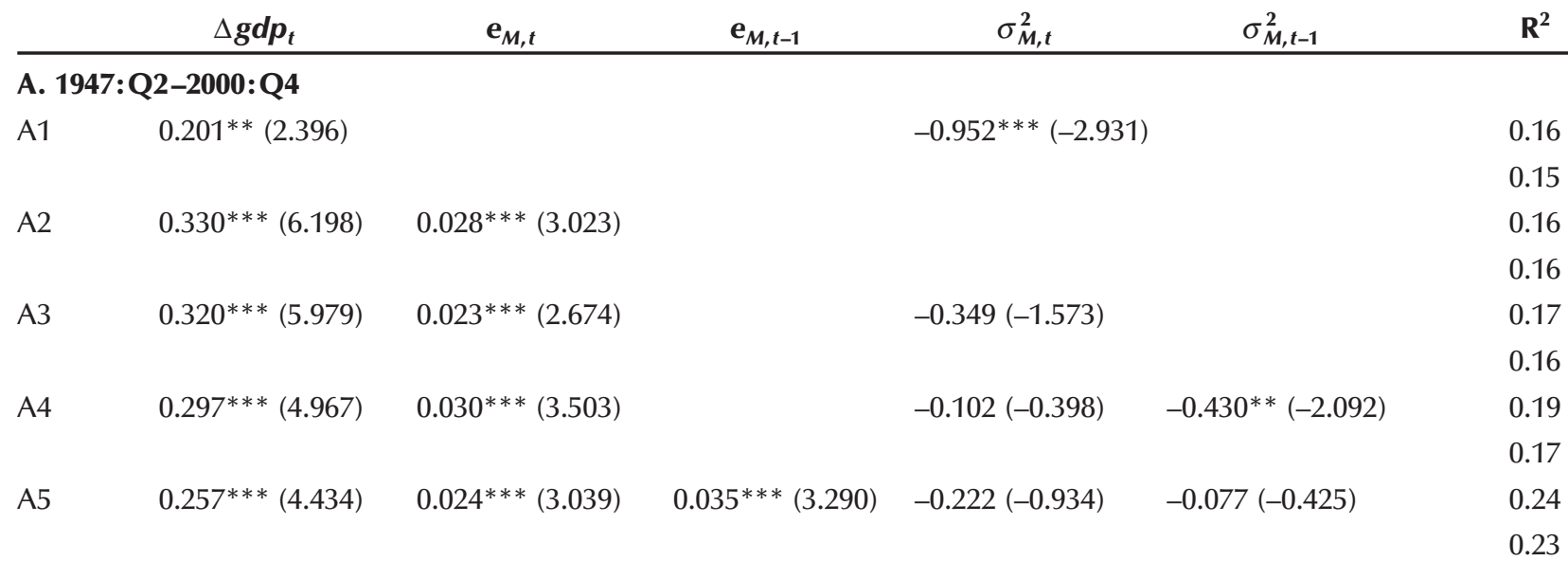

\section{B. 1963:Q1-1997:Q4}

B1 $0.322^{* * *}(5.892)$

$-0.547^{* *}(-2.073) \quad 0.15$

B2

$0.293 * * *(3.399) \quad 0.024 * *(2.506)$

0.14

$0.218^{* *}(2.343) \quad 0.014(1.355)$

$-0.783^{* *}(-2.383)$

0.13

B3

(1)

B4

$0.200 *(1.879) \quad 0.020 *(1.777)$

$-0.551^{*}(-1.661) \quad-0.364(-0.905)$

0.12

B5

$0.179 *(1.891) \quad 0.014(1.476)$

$0.027^{* *}(2.300)$

$-0.615^{* *}(-2.173) \quad-0.017(-0.050)$

0.18

0.16

0.18

0.16

0.23

0.21

\section{1885:Q4-2000:Q4}

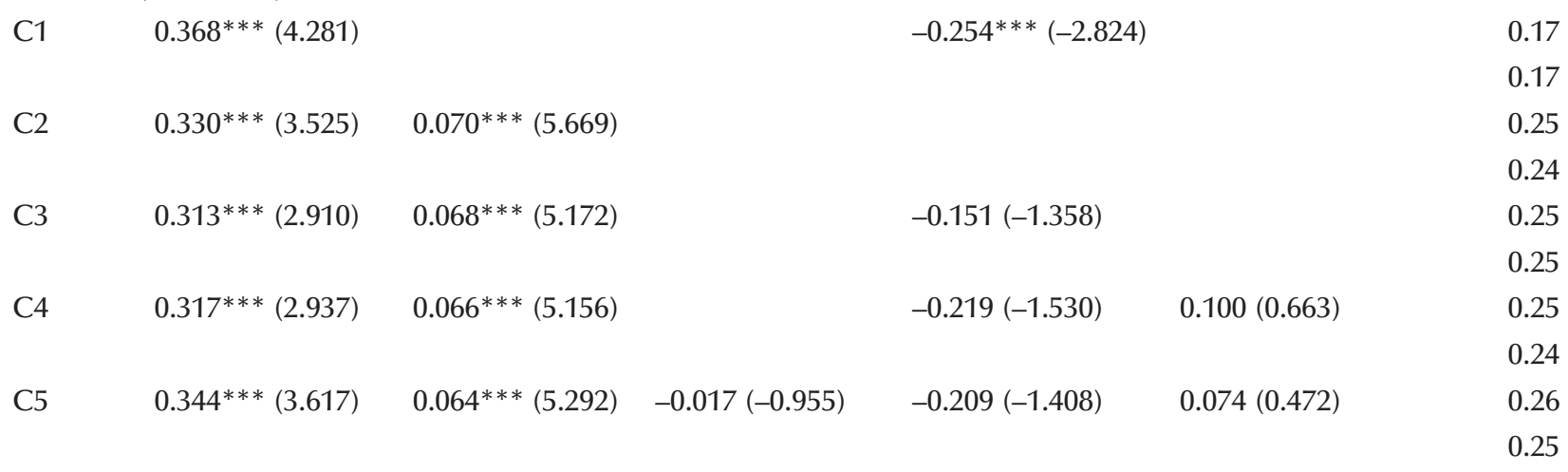

NOTE: $\mathrm{t}$ statistics are reported in parentheses and */**/*** denote significance at 10/5/1 percent levels, respectively (two-tailed tests). For the column under $R^{2}$, the first row is $R^{2}$ and the second row is the adjusted $R^{2}$. 


\section{Table 4}

\section{One-Quarter-Ahead Forecasts of GDP Growth: Nested Comparisons}

\begin{tabular}{|c|c|c|c|c|}
\hline \multirow[b]{2}{*}{$\mathrm{MSE}_{\mathrm{A}} / \mathrm{MSE}_{\mathrm{B}}$} & \multicolumn{2}{|c|}{ ENC-NEW } & \multicolumn{2}{|c|}{ MSE-F } \\
\hline & Statistic & Asy. CV & Statistic & Asy. CV \\
\hline \multicolumn{5}{|c|}{ A. Variance in benchmark model } \\
\hline 0.94 & 24.06 & 2.88 & 9.17 & 1.71 \\
\hline \multicolumn{5}{|c|}{ B. Return in benchmark model } \\
\hline 1.02 & 2.06 & 2.88 & -2.62 & 1.71 \\
\hline
\end{tabular}

NOTE: $\mathrm{MSE}_{\mathrm{A}}\left(\mathrm{MSE}_{\mathrm{B}}\right)$ is the mean-squared-error of the augmented (benchmark) model. See Appendix C for details about the ENC-NEW and MSE-F tests.

Three statistics are calculated to compare the performance of the augmented model with the performance of the respective benchmark model. The first statistic is the mean-squared-error ratio. The second one is the encompassing test (ENC-NEW) developed by Clark and McCracken (1999). The ENC-NEW statistic tests the null hypothesis that the benchmark model encompasses all the relevant information for one-quarter-ahead GDP growth; the alternative hypothesis of panel A (panel B) states that the return (variance) variables provide additional information. The third statistic is the equal forecast accuracy test (MSE-F) developed by McCracken (1999). The null hypothesis states that the benchmark model has a mean-squared forecasting error less than or equal to the error of the augmented model; the alternative is that the augmented model has a smaller mean-squared error. Clark and McCracken (1999) show that these two tests have the best overall power and size properties. I provide some details about these two tests in Appendix C. The columns titled "Asy. CV" report the 95 percent asymptotic critical values provided by Clark and McCracken (1999) and McCracken (1999). I use the period 1947:Q3 to 1965:Q1 for the initial in-sample regression and use the regression results to forecast GDP growth in 1965:Q2. The insample regression is updated recursively. That is, I then use the period 1947:Q3 to 1965:Q2 to make a forecast for the GDP growth in 1965:Q3 and so on. Panel A shows that incorporating the return variables reduces the forecasting error. The mean-squarederror of the augmented model amounts to only 94 percent of the mean-squared-error of the benchmark model. Also, the ENC-NEW and MSE-F tests reject the null hypotheses overwhelmingly. Hence, the out-of-sample forecast tests in panel A provide strong evidence that excess returns contain information about future output beyond variance. On the other hand, panel B shows that the augmented model exhibits a higher mean-squared-error than the benchmark model. Moreover, in panel B the null hypotheses are not rejected at the conventional significance levels for either the ENC-NEW or the MSE-F tests. Therefore, I cannot reject the null hypothesis that returns subsume the information content of variance in forecasting real output growth.

\section{CONCLUSION}

In this article, I show that there is a close link between stock market returns and volatility. That is, because volatility is serially correlated, returns relate positively to past volatility, but relate negatively to contemporaneous volatility. Therefore, stock market volatility forecasts output because volatility affects the cost of capital through its link with expected stock market return. From the cost-ofcapital point of view, volatility contains no additional output-forecasting information beyond the information that returns provide, although the positive relation between returns and past volatility weakens the predictive power of returns in certain specifications. On the other hand, stock market returns do contain information about future economic activity beyond volatility (e.g., information about future cash flows). Therefore, if the cost of capital is the main channel through which volatility affects future output, it should follow that stock market returns have a more important role in forecasting economic activity than volatility does. I show that this hypothesis is supported by the in-sample and out-of-sample regression results using postwar data. 


\section{REFERENCES}

Barro, Robert J. “The Stock Market and Investment.” Review of Financial Studies, 1990, 3(1), pp. 115-31.

Black, Fischer, and Scholes, Myron S. "The Pricing of Options and Corporate Liabilities." Journal of Political Economy, May/June 1973, 81(3), pp. 637-54.

Campbell, John Y. "Stock Returns and the Term Structure." Journal of Financial Economics, June 1987, 18(2), pp. 373-99.

; Lettau, Martin; Malkiel, Burton G. and Xu, Yexaio. "Have Individual Stocks Become More Volatile? An Empirical Exploration of Idiosyncratic Risk." Journal of Finance, February 2001, 56(1), pp. 1-43.

; Lo, Andrew and MacKinlay, A. Craig. The Econometrics of Financial Markets. Princeton: Princeton University Press, 1997.

Clark, Todd E. and McCracken, Michael W. "Tests of Equal Forecast Accuracy and Encompassing for Nested Models." Working Paper No. 99-11, Federal Reserve Bank of Kansas City, October 1999.

Cochrane, John H. "Production-Based Asset Pricing and the Link Between Stock Returns and Economic Fluctuations." Journal of Finance, March 1991, 46(1), pp. 209-37.

Dueker, Michael J. “The News Effect of Time-Varying Kurtosis on Stock Returns.” Working paper, University of Washington, 1991.

Fama, Eugene F. "Stock Return, Real Activity, Inflation, and Money." American Economic Review, September 1981, 71(4), pp. 545-65.

Fisher, Stanley and Merton, Robert C. "Macroeconomics and Finance: The Role of the Stock Market." CarnegieRochester Conference Series on Public Policy, Autumn 1984, 21(0), pp. 57-108.

French, Kenneth R.; Schwert, G. William and Stambaugh, Robert F. "Expected Stock Returns and Volatility." Journal of Financial Economics, September 1987, 19(1), pp. 3-30.

Gordon, Robert J. The American Business Cycle. Chicago: The University of Chicago, 1986.

Guo, Hui. "Understanding the Risk-Return Tradeoff in the Stock Market.” Working Paper No. 2002-001A, Federal Reserve Bank of St. Louis, 2002. and Whitelaw, Robert. "Risk and Return: Some New Evidence.” Working Paper 2001-A, Federal Reserve Bank of St. Louis, 2001.

Lamont, Owen A. "Investment Plans and Stock Returns." Journal of Finance, December 2000, 55(6), pp. 2719-45.

Lilien, David M. "Sectoral Shifts and Cyclical Unemployment." Journal of Political Economy, August 1982, 90(4), pp. 777-93.

McCracken, Michael W. "Asymptotics for Out-of-Sample Tests of Causality.” Working paper, Louisiana State University, 1999.

Merton, Robert C. "An Intertemporal Capital Asset Pricing Model.” Econometrica, September 1973, 41(5), pp. 867-87.

"On Estimating the Expected Return on the Market: An Exploratory Investigation.” Journal of Financial Economics, December 1980, 8(4), pp. 323-61.

Newey, Whitney K. "A Simple, Positive Semidefinite, Heteroskedasticity and Autocorrelation Consistent Covariance Matrix.” Econometrica, May 1987, 55(3), pp. 703-08.

and West, Kenneth D. "Automatic Lag Selection in Covariance Matrix Estimation." Review of Economic Studies, October 1994, 61(4), pp. 631-54.

Pindyck, Robert S. "Risk Aversion and Determinants of Stock Market Behavior.” Review of Economics and Statistics, May 1988, 70(2), pp. 183-90.

Schwert, G. William. "Business Cycles, Financial Crises, and Stock Volatility." Carnegie-Rochester Conference Series on Public Policy, Autumn 1989a, 31(0), pp. 83-126.

"Why Does Stock Market Volatility Change Over Time?" Journal of Finance, December 1989b, 44(5), pp. 1115-53.

"Indexes of U.S. Stock Prices from 1802 to 1987." Journal of Business, July 1990, 63(3), pp. 399-426.

Scruggs, John T. "Resolving the Puzzling Intertemporal Relation Between the Market Risk Premium and Conditional Market Variance: A Two-Factor Approach.” Journal of Finance, April 1998, 53(2), pp. 575-603.

Shiller, Robert J. "Do Stock Prices Move Too Much To Be Justified by Subsequent Changes in Dividends?" American Economic Review, June 1981, 71(3), pp. 421-36. 
Turner, Christopher; Startz, Richard and Nelson, Charles R. "A Markov Model of Heteroskedasticity, Risk, and Learning in the Stock Market." Journal of Financial Economics, November 1989, 25(1), pp. 3-22.

Yang, Dennis, and Zhang, Qiang. "Drift-Independent Volatility Estimation Based on High, Low, Open, and Close Prices.” Journal of Business, July 2000, 73(3), pp. 477-91.

\section{Appendix A}

\section{DATA DESCRIPTION}

The daily excess stock market return is the difference between the daily stock market return and the daily risk-free rate. I use the daily market return constructed by Schwert (1990) before July 2, 1962 , and use the daily value-weighted stock market return obtained from the Center for Research in Security Prices (CRSP) through the end of the year 2000; thereafter I use the daily S\&P 500 index. The risk-free rate is the commercial paper rate from Appendix B of Gordon (1986) before 1926 and is obtained from CRSP thereafter. The risk-free rate is available only at a monthly frequency. I calculate a daily risk-free rate from monthly observations by dividing by the number of trading days in the respective month. Thus I assume that the daily risk-free rate is constant within each month. I aggregate the daily excess return to quarterly obser- vation, $e_{M, t}$. The stock market variance, $\sigma_{M, t}$, is calculated as the sum of squared deviations from the mean of daily excess stock market returns:

$$
\sigma_{M, t}=\sum_{j=1}^{\tau}\left(e_{M, t \tau}-\bar{e}_{M, t}\right)^{2},
$$

where $e_{M, t}$ is the excess return of day $\tau$ in quarter $t$ and $\bar{e}_{M, t}$ is the average daily excess return of quarter $t$. The quarterly real GDP data are obtained from the Bureau of Economic Analysis (BEA). The data of real GNP before 1947:Q1 are from Appendix B of Gordon (1986) and from the BEA thereafter. The growth rates of GDP (GNP) are calculated as differences in logarithmic values (log growth rates). Source: CRSP, Center for Research in Security Prices. Graduate School of Business, The University of Chicago, 2002. Used with permission. All rights reserved. < www.crsp.uchicago.edu > 


\section{Appendix B}

\section{A LOG-LINEAR ASSET PRICING MODEL}

Using a log-linearization method, Campbell et al. (1997) show that excess stock market return, $e_{M, t+1}$, can be approximately expressed as

(A1)

$$
\begin{aligned}
& e_{M, t+1} \approx E_{t} e_{M, t+1}+\left(E_{t+1}-E_{t}\right) \\
& {\left[\sum_{j=0}^{\infty} \rho^{j} \Delta d_{t+1+j}-\sum_{j=1}^{\infty} \rho^{j} \Delta e_{M, t+1+j}-\sum_{j=1}^{\infty} \rho^{j} r_{f, t+1+j}\right],}
\end{aligned}
$$

where $\Delta d_{t+1+j}$ is the growth rate of the dividend, $r_{f, t+1+j}$ is the real risk-free rate, and $\rho$ is a constant. Substituting equation (1) into (A1), I obtain

(A2)

$$
\begin{aligned}
e_{M, t+1} & \approx \gamma E_{t} \sigma_{M, t+1}^{2} \\
& -\left(E_{t+1}-E_{t}\right)\left[\sum_{j=1}^{\infty} \rho^{j} \sigma_{M, t+1+j}^{2}\right]+\eta_{d, t+1}+\eta_{f, t+1},
\end{aligned}
$$

where

$$
\eta_{d, t+1}=\left(E_{t+1}-E_{t}\right)\left[\sum_{j=0}^{\infty} \rho^{j} \Delta d_{t+1+j}\right]
$$

and

$$
\eta_{f, t+1}=-\left(E_{t+1}-E_{t}\right)\left[\sum_{j=1}^{\infty} \rho^{j} r_{f, t+1+j}\right] .
$$

Substituting equation (2) into equation (A2), I obtain (A3)

$$
e_{M, t+1} \approx \gamma \alpha+\gamma \beta \sigma_{M, t}^{2}-\frac{\gamma \rho \beta}{1-\rho \beta} \varepsilon_{t+1}+\eta_{d, t+1}+\eta_{f, t+1} .
$$

I can rewrite equation (2) as

$$
\varepsilon_{t+1}=\sigma_{M, t+1}^{2}-\alpha-\beta \sigma_{M, t}^{2} .
$$

Substituting equation (2)' into equation (A3), I obtain

$$
\begin{aligned}
e_{M, t+1} & \approx \frac{\gamma \cdot \alpha}{1-\rho \cdot \beta}+\frac{\gamma \beta}{1-\rho \beta} \sigma_{M, t}^{2} \\
& -\frac{\gamma \rho \beta}{1-\rho \beta} \sigma_{M, t+1}^{2}+\eta_{d, t+1}+\eta_{f, t+1} .
\end{aligned}
$$

Campbell et al. (1997) show that shocks to the real risk-free rate, $\eta_{f, t+1}$, explain little of the variation in excess stock market returns. By setting $\eta_{f, t+1}$ equal to zero, (A3) and (A4) become equations (3) and (4), respectively.

\section{Appendix C}

\section{ENCOMPASSING (ENC-NEW) TEST AND EQUAL FORECAST ACCURACY (MSE-F) TEST}

Suppose that there are $T+1$ observations. The first $R$ observations are used in the initial in-sample regression. The forecasting error for period $R+1$ is $\hat{u}_{B, R+1}$ for the benchmark model and $\hat{u}_{A, R+1}$ for the augmented model. Then estimates of the forecasting equations are updated using the first $R+1$ observations and used to forecast the next period, $R+2$. The forecasting error for period $R+2$ is $\hat{u}_{i, R+2}, i=A, B$. Forecasts are recursively updated to generate a time series of one-period-ahead forecasting errors $\left\{\hat{u}_{i, \tau}\right\}, i=A, B$ and $\tau=R+1 \ldots T+1$, a total of $P=T+1-R$ observations.

The statistic of the ENC-NEW test is

$$
E N C-N E W=P \frac{P^{-1} \sum_{t=R}^{T}\left[\hat{u}_{B, t+1}^{2}-\hat{\mathfrak{u}}_{B, t+1} \hat{u}_{A, t+1}\right]}{P^{-1} \sum_{t=R}^{T} \hat{\mathfrak{u}}_{A, t+1}^{2}} .
$$

Clark and McCracken (1999) derive the asymptotic distribution of the ENC-NEW statistic under the null hypothesis that the augmented model encompasses the information of the benchmark model.

The MSE-F test statistic is

$$
M S E-F=\frac{\sum_{t=R}^{T}\left[\hat{u}_{B, t+1}^{2}-\hat{u}_{A, t+1}^{2}\right]}{P^{-1} \sum_{t=R}^{T} \hat{u}_{A, t+1}^{2}} .
$$

McCracken (1999) derives the asymptotic distribution of the MSE-F statistic under the null hypothesis that the augmented model has a smaller meansquared forecasting error than the benchmark model does. 
